\title{
Aplicação Mobile Para Auxiliar o Ensino e Aprendizagem do Alfabeto na Pré-escola
}

\author{
Fausto Brito da Silva Junior ${ }^{1}$, Zenaide Carvalho da Silva ${ }^{1}$ \\ ${ }^{1}$ Universidade Federal do Sul e Sudeste do Pará (UNIFESSPA) \\ Folha 17, Quadra 04, Lote Especial - 68505-080 - Marabá - PA - Brasil \\ \{fausto22, zenaide.silva\}@unifesspa.edu.br
}

\begin{abstract}
This article presents a mobile application called ABC Illustrated, developed to assist pre-school teachers and elementary school teachers in the classroom, enabling the teaching and learning of the alphabet for children in preschool or in the 1st year of elementary school aged 3 to 6 years, teaching several words that are made available in the application. The Illustrated ABC seeks to explore the knowledge of the alphabet, in addition to other concepts of children's daily life such as fruits, means of transportation, human body, colors, geometric shapes, numbers and animals, aiming to help in teaching and learning of children who are in the literacy phase in a fun and playful way.
\end{abstract}

Resumo. Este artigo apresenta uma aplicação mobile denominada $A B C$ Ilustrado, desenvolvida para auxiliar os professores da pré-escola e do $1^{a}$ ano do ensino fundamental nas salas de aulas, possibilitando o ensino e a aprendizagem do alfabeto para crianças que estão na pré-escola ou no $1^{a}$ ano do ensino fundamental com idade entre 3 a 6 anos, ensinando várias palavras que são disponibilizadas no aplicativo. $O$ ABC Ilustrado buscar explorar o conhecimento do alfabeto, além de outros conceitos do cotidiano das crianças como frutas, meios de transporte, corpo humano, cores, formas geométricas, números e animais, objetivando auxiliar no ensino-aprendizagem das crianças que estão em fase de alfabetização de forma lúdica e divertida.

\section{Introdução}

Alfabetização é o processo pelo qual se adquire o domínio de um código e das habilidades de utilizá-lo para ler e escrever, ou seja, "o domínio da tecnologia - do conjunto de técnicas - para exercer a arte e ciência da escrita". O exercício efetivo e competente da tecnologia da escrita denomina-se Letramento que implica várias habilidades, tais como, capacidade de ler ou escrever para atingir diferentes objetivos [Ribeiro 2003].

Para Almeida (2012), o processo de alfabetização com auxílio do computador é possível, pois abre possibilidades para que os alunos tenham uma nova e eficaz maneira de desenvolvimento da autonomia, curiosidade e criatividade promovendo a construção do conhecimento da criança.

Possuir um laboratório de informática não torna a escola apta ao uso da tecnologia, ou seja, apenas possibilita que ela tem acesso à mesma. É necessário orientar os profissionais e os alunos de que é necessário saber utilizar esta ferramenta para a 
VII Congresso Brasileiro de Informática na Educação (CBIE 2018)

Anais dos Workshops do VII Congresso Brasileiro de Informática na Educação (WCBIE 2018)

busca e, principalmente, para a seleção de informações, permitindo-os compreender e atuar na formação de seu entorno [Bernardi 2010].

Neste contexto é apresentado um aplicativo ABC Ilustrado para auxiliar o ensino e aprendizagem do alfabeto além de várias palavras do cotidiano das crianças, indicado para os alunos que estão na pré-escola ou no $1^{\mathrm{a}}$ ano do ensino fundamental, com faixa etária entre 3 a 6 anos de idade. O aplicativo apresenta oito categorias, a saber, "alfabeto", "frutas", "meios de transporte", "corpo humano", "cores", "formas geométricas" e "animais", as quais os professores poderão explorar nas suas aulas, mostrando as imagens que vão aparecer no aplicativo para seus alunos e fazendo perguntas sobre o que tem na imagem. A categoria principal "alfabeto" servirá como base para demais categorias, trabalhando as mesmas de acordo com a metodologia que os professores considerarem melhor para o entendimento dos alunos. O aplicativo disponibiliza recurso acessível de áudio descrição que beneficiará especialmente crianças com deficiência visual e baixa visão.

Através do aplicativo os alunos podem ter uma percepção melhor da escrita de algumas palavras mostradas nas imagens, bem como vogais e consoantes, além de contar com áudio descrição da pronúncia da palavra. Como por exemplo: o aluno ao selecionar a opção alfabeto, e ao escolher essa categoria o aplicativo apresenta uma imagem de como se escreve a letra "A" em maiúscula e minúscula, e uma palavra que essa letra forma, além da descrição em áudio, esse processo será feito até chegar na última letra do alfabeto. Para uma melhor fixação do aprendizado e disponibilizado uma opção que apresenta um play de música que toca uma música referente a cada categoria escolhida.

O presente trabalho está estruturado em 5 seções. A seção 2 apresenta os trabalhos relacionados, na seção 3 é apresentado o aplicativo com as principais funcionalidades, a seção 4 apresenta os resultados. Por fim, na seção 5 a conclusão.

\section{Trabalhos Relacionados}

Nesta seção vamos destacar três trabalhos que foram pesquisados que se relacionam com a temática em questão. Foram selecionados esses aplicativos voltados para educação infantil, pois eles apresentam algumas funcionalidades similares com o aplicativo apresentado nesse trabalho.

O trabalho de Junior (2017) apresenta um aplicativo para alfabetização e letramento de crianças com síndrome de Down, o aplicativo que se chama "Meu ABC Down" permite que uma galeria de mídias de sons, imagens e textos sejam geradas pela própria criança, a partir do contexto histórico-social, o mesmo dispõe de dois jogos, o "Jogo de Memória" e o "Acerte a Imagem". O aplicativo possui algumas adaptações devido as características das pessoas que possuem síndrome de Down, essas adaptações referem-se alguns requisitos não funcionais, como por exemplo, o teclado que possui letras maiores que o habitual, tendo em vista a dificuldade visual e motora do público alvo, os ícones e imagens utilizadas no jogo são grandes e sempre utiliza o maior espaço possível da tela do tablet, assim melhorando a visualização para o usuário e aumentando a área de clique na imagem ou ícone, diminuindo a chance de erro na hora de clicar, tendo em vista as complicações na coordenação motora que estas crianças possuem, além de outras adaptações. 
VII Congresso Brasileiro de Informática na Educação (CBIE 2018)

Anais dos Workshops do VII Congresso Brasileiro de Informática na Educação (WCBIE 2018)

O trabalho de Juttel et al (2015) apresenta um aplicativo para auxiliar a alfabetização utilizando a realidade aumentada, os autores do trabalho criaram um livro com 26 páginas, cada página tem uma letra do alfabeto no formato 3D para interagir com o aplicativo que é denominado "Alfabeto Aumentado", essas letras são apresentadas na tela do dispositivo móvel através do reconhecimento dos marcadores das páginas do livro, esse reconhecimento é feito através da câmera do dispositivo, quando o aplicativo faz o reconhecimento de umas das letras do alfabeto que se encontra no livro, é apresentado para o usuário uma imagem correspondente a letra e quatro figuras que iniciam com a mesma letra, além do áudio descrição das imagens.

O trabalho de Kobayashi et al (2015) apresenta o aplicativo língua de gato, que é um jogo de palavras cruzadas com elementos do universo da criança. O uso do língua de gato pressupõe dois papéis: o do usuário responsável por criar o jogo de palavras cruzadas (mediador) inserindo um conjunto de palavras e dicas a do usuário que vai jogar as palavras cruzadas (criança em fase de aquisição de leitura e escrita). O aplicativo ensina as crianças a escreverem palavras do seu cotidiano através de palavras cruzadas. Para completar a cruzada a criança deve arrastar a letras que aparecem distribuídas pelo "tabuleiro" a cada palavra inserida. A criação de um jogo possui 2 tipos de "dicas": visuais ou auditivas. Por exemplo, ao adicionar a palavra "sorvete" pode-se inserir uma dica tirando uma foto do "sorvete" ou selecionando através da galeria do dispositivo ou gravando um áudio da voz do mediador dizendo a palavra "sorvete".

A partir da análise dos trabalhos relacionados realizamos uma comparação entre os aplicativos apresentados e o nosso aplicativo $\mathrm{ABC}$ Ilustrado, em relação às funcionalidades/requisitos apresentados.

A aplicação desenvolvida inclui em suas funcionalidades áudio descrição e músicas, para tornar o aplicativo acessível às crianças com deficiência visual e baixa visão. O Quadro 1 mostra um comparativo dos aplicativos analisados em relação ao aplicativo mobile desenvolvido no trabalho.

Quadro 1. Comparação entre os aplicativos estudados e do aplicativo mobile desenvolvido.

\begin{tabular}{|c|c|c|c|c|c|c|c|}
\hline Aplicativos & $\begin{array}{c}\text { Idioma } \\
\text { português }\end{array}$ & $\begin{array}{c}\text { Áudio } \\
\text { descrição }\end{array}$ & Música & Grátis & $\begin{array}{l}\text { Off- } \\
\text { line }\end{array}$ & $\begin{array}{c}\text { Direcionado } \\
\text { a crianças } \\
\text { da } \\
\text { pré-escola }\end{array}$ & $\begin{array}{l}\text { Letras } \\
\text { Cursivas }\end{array}$ \\
\hline $\begin{array}{l}\text { Meu ABC } \\
\text { Down }\end{array}$ & 1 & $\checkmark$ & & $\checkmark$ & & 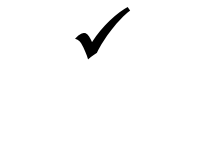 & \\
\hline $\begin{array}{l}\text { Alfabeto } \\
\text { Aumentado }\end{array}$ & $\checkmark$ & $\checkmark$ & & $\sqrt{ }$ & & $\checkmark$ & \\
\hline
\end{tabular}


VII Congresso Brasileiro de Informática na Educação (CBIE 2018)

Anais dos Workshops do VII Congresso Brasileiro de Informática na Educação (WCBIE 2018)

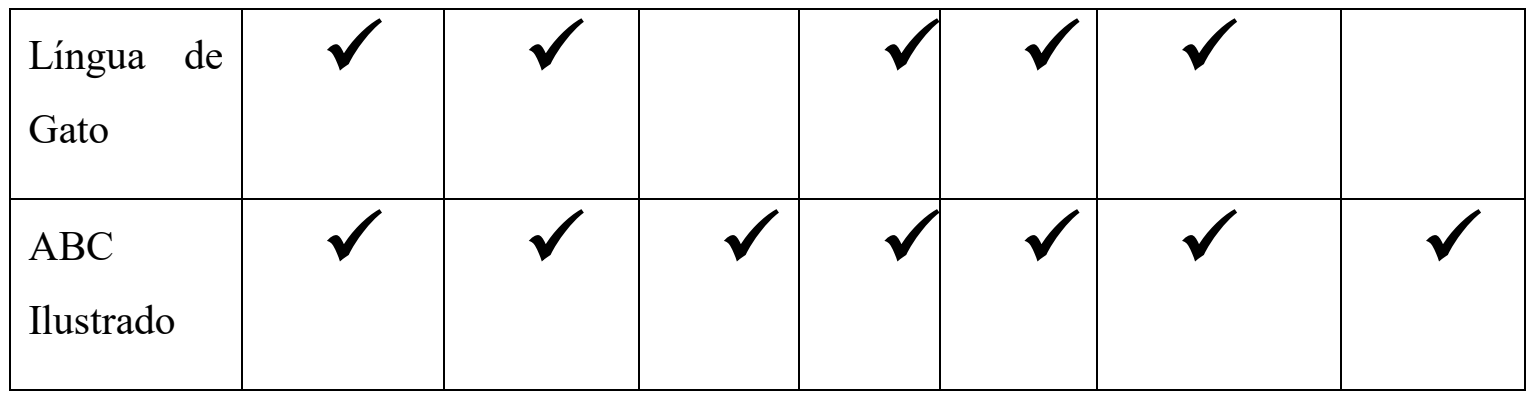

Analisando o Quadro 1, podemos verificar que nenhum dos aplicativos apresentados nos trabalhos relacionados não apresentam músicas para reforçar a aprendizagem dos seus conteúdos, já o ABC Ilustrado disponibiliza um play de música, que toca uma música infantil referente a cada categoria escolhida, assim os alunos poderão contar com mais um recurso para auxiliar a aprendizagem, dessa maneira o app apresenta um conjunto de funcionalidades e recursos, como "figuras", "palavras", "letras", "áudio descrição" e "músicas", nenhum dos aplicativos estudados não exploram as letras cursivas da maneira apresentada no ABC Ilustrado. Todos os aplicativos são direcionados para crianças da pré-escola, todos utilizam áudio descrição e nenhum deles precisam de internet para apresentar seus conteúdos.

\section{Aplicação Mobile Para Auxiliar o Ensino e Aprendizagem do Alfabeto na Pré-escola}

Para o desenvolvimento do aplicativo foi utilizado a IDE Android Studio 3.1 que é um ambiente de desenvolvimento integrado para desenvolver para plataforma Android, utiliza Java como linguagem de programação e $X M L$, que é uma linguagem de marcação, para criação de interface gráfica do usuário.

O ABC Ilustrado se utilizou da API Level 19 para versão mínima 4.4 mais conhecida como KitKat, sendo necessário para instalação do app um celular com sistema operacional Android que atenda os requisitos da versão mínima exigida 4.4 ou superior.

Segundo Mayer (2005), a aprendizagem multimídia é fundamentada na hipótese que de "as mensagens educacionais ou instrucionais multimídia" são concebidas ou geradas a partir da forma como a mente humana funciona, têm mais probabilidade de levar a que haja uma aprendizagem significativa do que as outras que não o são.

A aprendizagem multimídia destaca que a aprendizagem é mais significativa combinando palavras e imagens do que apenas através de palavras. Não se garante a melhoria da aprendizagem simplesmente juntando imagens às palavras, é necessário que uma apresentação multimídia esteja desenhada de acordo com o modo como a informação é processada pelo ser humano.

Diante desde contexto o aplicativo foi desenvolvido pensando em vários aspectos, que possa auxiliar as crianças no ensino-aprendizagem do alfabeto e de várias palavras, através de figuras ilustradas, palavras, áudio descrição, letras e músicas.

$\mathrm{O}$ aplicativo ABC Ilustrado tem o intuído de proporcionar a possibilidade de se adquirir o conhecimento aliado ao entretimento. Seu objetivo está focado no ensino e aprendizagem do Alfabeto na pré-escola e de várias palavras que fazem parte do 
VII Congresso Brasileiro de Informática na Educação (CBIE 2018)

Anais dos Workshops do VII Congresso Brasileiro de Informática na Educação (WCBIE 2018)

cotidiano das crianças. O aplicativo disponibiliza oito categorias que são representadas por figuras ilustradas, áudio descrição e músicas, para facilitar o entendimento das atividades.

$\mathrm{Na}$ Figura 1 é demostrado a tela inicial do aplicativo $\mathrm{ABC}$ Ilustrado, são apresentadas as categorias do aplicativo, essas opções podem ser percorridas deslizandose o dedo pela tela para a "esquerda" ou para "direita". Os itens se movem na direção do dedo dependendo do movimento do dedo, esse modo de navegação é como se fosse um carrossel.

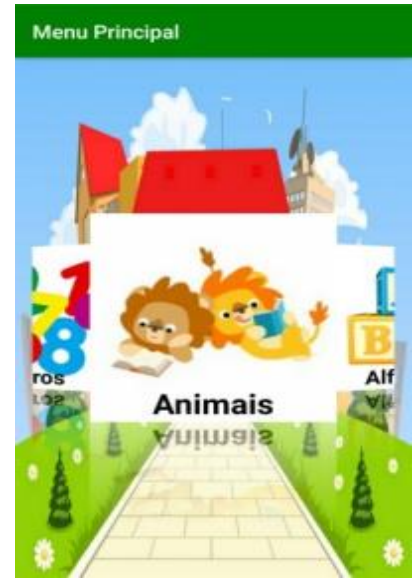

Figura 1. Tela do Menu Principal.

A Figura 2 apresenta todas as categorias que o aplicativo disponibiliza para os usuários, essas categorias são acessadas através de um menu principal que está representado na Figura 1, no total são oito opções: "frutas", "corpo humano", "cores", "meios de transporte", "formas geométricas", "números", "alfabeto" e "animais".
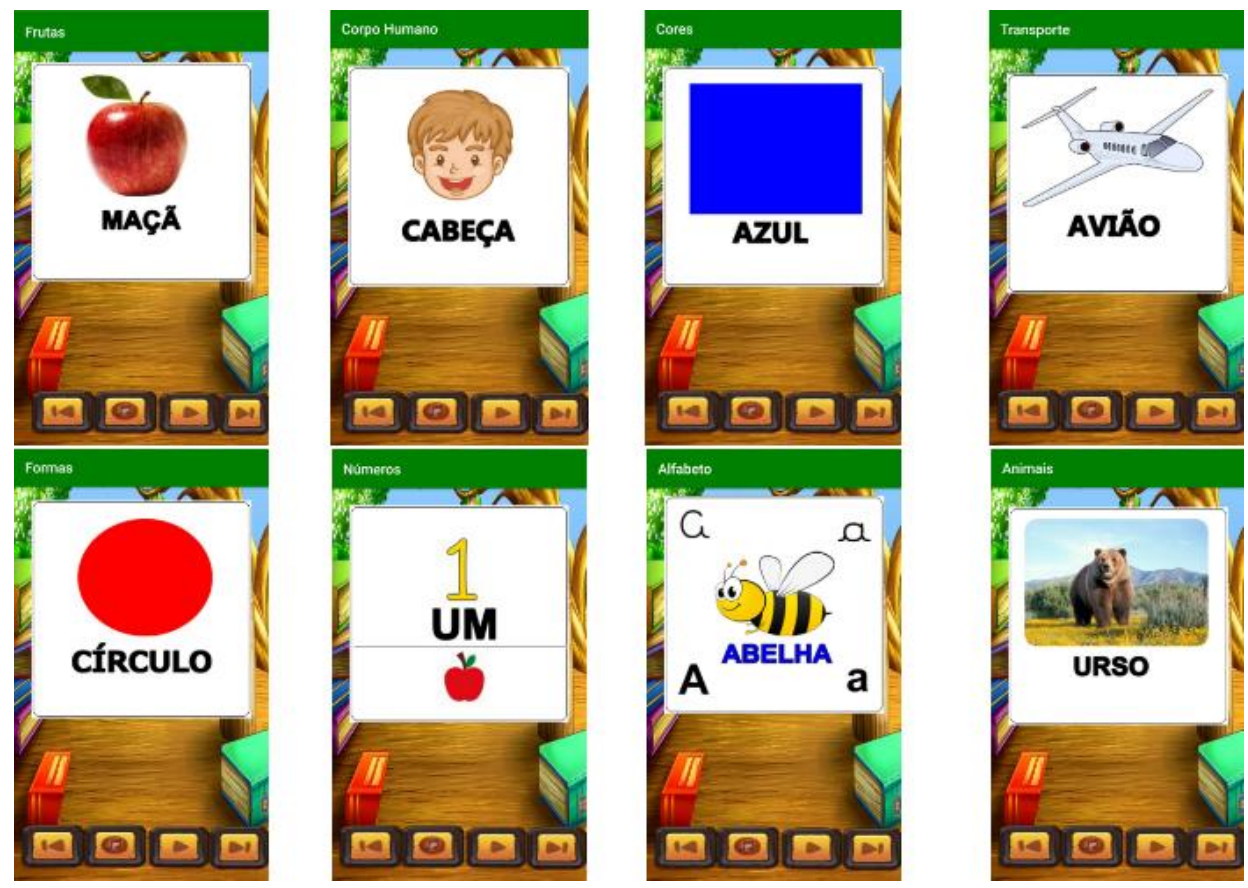

Figura 2. Telas das oito categorias do aplicativo. 
VII Congresso Brasileiro de Informática na Educação (CBIE 2018)

Anais dos Workshops do VII Congresso Brasileiro de Informática na Educação (WCBIE 2018)

Na Figura 3, é apresentado o resultado do clique do botão na categoria "alfabeto", ao entrar nessa categoria automaticamente é ativado o áudio descrição da figura ilustrada, com letras cursivas maiúsculas e minúsculas, mais duas letras maiúsculas e minúsculas dispostas nos cantos da figura, uma palavra em caixa alta que essa letra forma, e uma imagem representando a palavra localizada no centro da figura.

Essas figuras podem se passadas deslizando o dedo para "esquerda" ou "direita", ao deslizar o dedo para a "esquerda" o aplicativo apresenta a próxima figura, e para voltar basta deslizar o dedo para "direita", as figuras poderão também se passadas através dos botões "próximo" e "anterior" destacados no detalhe 1 e 4 da Figura 3.
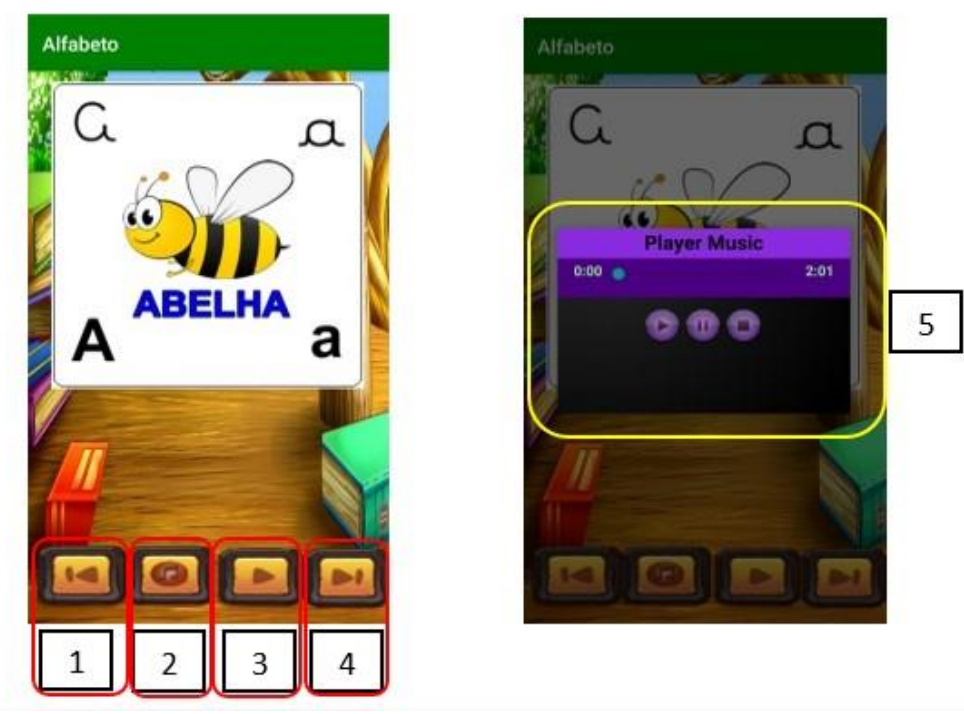

Figura 3. Categoria Alfabeto.

No detalhe 2 da Figura 3 quando clicado, é disponibilizado um play de música que está representado no detalhe 5 da Figura 3, que tocará uma música com o tema da categoria escolhida, o detalhe 3 da Figura 3 repete o áudio descrição da figura ilustrada, o mesmo acontece quando clicado em cima da figura, as demais categorias vão seguir o mesmo fluxo de atividade descrito na Figura 3, o que altera são as figuras, áudio descrição e as músicas tocadas em cada play de música.

Antes do desenvolvimento do aplicativo foram feitos alguns levantamentos de requisitos funcionais e não funcionais para auxiliar no processo de análise de requisitos do aplicativo, organizando os objetivos que o aplicativo deveria alcançar, participaram desse levantamento professoras da escola participante do experimento.

As figuras utilizadas no aplicativo foram selecionadas de acordo com a solicitação das professoras participantes do experimento de levantamento de requisitos do aplicativo, através dos relatos das mesmas, que já utilizavam essas figuras ilustradas para o ensino e aprendizagem do alfabeto durante suas aulas. Inclusive as professoras solicitaram que essas figuras seguissem um padrão, como por exemplo: fundo branco, imagem sempre no centro da figura, letras maiúsculas do lado esquerdo e minúscula do direito, assim como a palavra em caixa alta embaixo da imagem que faz referência a palavra, esses requisitos tem um objetivo de não confundir muito a mente dos alunos durante o processo de aprendizagem. 
VII Congresso Brasileiro de Informática na Educação (CBIE 2018)

Anais dos Workshops do VII Congresso Brasileiro de Informática na Educação (WCBIE 2018)

Uma versão do Aplicativo foi disponibilizada online, para realizar o download do aplicativo, acessar o link https://bit.ly/2NImAhF. Também encontra-se no link https://youtu.be/nDrfQbU2QYM um vídeo demonstrativo do aplicativo ABC Ilustrado.

\section{Resultados}

Foi planejado e executado um estudo de caso como forma de uma avaliação preliminar para verificar se o ABC Ilustrado atende aos requisitos que foram definidos anteriormente com as professoras participantes do levantamento de requisitos do aplicativo. O estudo de caso ocorreu na Escola Silvino Santis, localizada na cidade de Marabá-PA no bairro Nova Marabá, a referida escola atende alunos de $1^{\mathrm{a}}$ a $4^{\mathrm{a}}$ série do Ensino Fundamental.

A exposição do aplicativo foi realizada na sala de aula para turma de $1^{\text {a }}$ série do ensino fundamental, essa demonstração foi feita utilizando um notebook contendo o programa BlueStacks instalado, que é um programa gratuito que permite que aplicativos Android sejam executados diretamente em computadores Windowns e Macintosh, e um Datashow da escola, pois assim toda a turma pôde visualizá-lo de uma só vez, facilitando o entendimento e o diálogo entre a professora da sala e os alunos.

A Figura 4 demonstra um momento do estudo de caso sendo realizado em sala de aula, com auxílio do notebook e Datashow, foi apresentado o aplicativo para os alunos, dessa maneira ficou mais interessante a participação de todos os alunos sem precisar que cada aluno tivesse um celular presente em mãos.

Através do ABC Ilustrado a professora adaptou o aplicativo ao conteúdo a ser trabalhado com a turma facilitando o entendimento do assunto e a construção do conhecimento fazendo o aluno sentir-se sujeito da sua própria aprendizagem.

A avaliação do aplicativo feita pelas professoras da turma de $1^{\circ}$ série do ensino fundamental foi positiva em todos os aspectos, estimulando a interação entre a professora e alunos, aguçando a curiosidade e a criatividade entre os mesmos, verificando-se o empenho e o desenvolvimento de cada um.

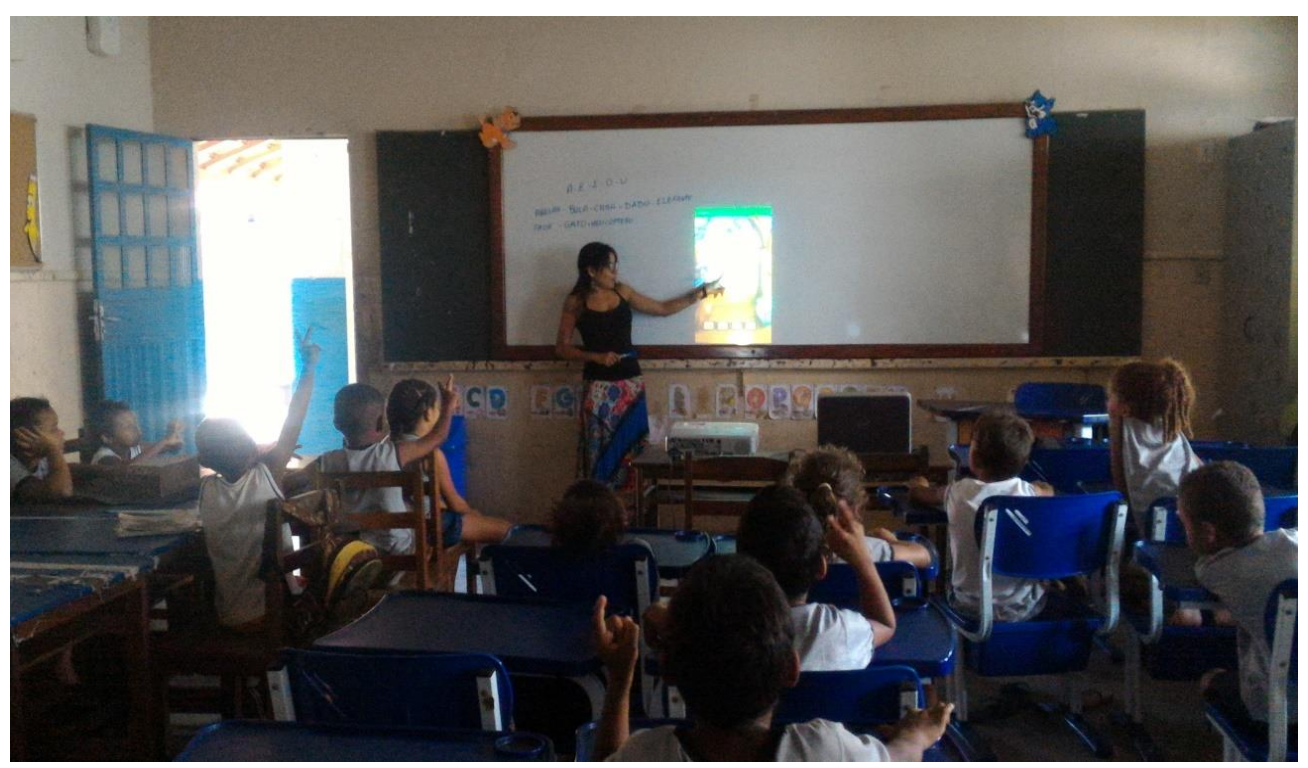

Figura 4. Utilização do aplicativo $A B C$ llustrado na sala de aula. 
VII Congresso Brasileiro de Informática na Educação (CBIE 2018)

Anais dos Workshops do VII Congresso Brasileiro de Informática na Educação (WCBIE 2018)

O ABC Ilustrado foi desenvolvido com ênfase no alfabeto e na construção de palavras do dia a dia dos alunos, portanto sua aplicação colabora no processo de ensinoaprendizagem, pois foi percebido na forma como os alunos participaram quando foi feito a demonstração em sala de aula, o ânimo e a alegria demonstrados por eles.

A Figura 5 apresenta a participação dos alunos, a professora convidou uma aluna para circular quais letras são vogais na imagem que aparece no aplicativo, estimulando assim a participação dos discentes. A cada figura que o ABC Ilustrado apresentava eram feitas perguntas sobre a mesma, como por exemplo: "quantas vogais têm na palavra, quantas consoantes existem na palavra, letras maiúsculas/minúsculas e letras cursivas", foi abordado também as músicas que cada categoria disponibiliza no play de mídia.

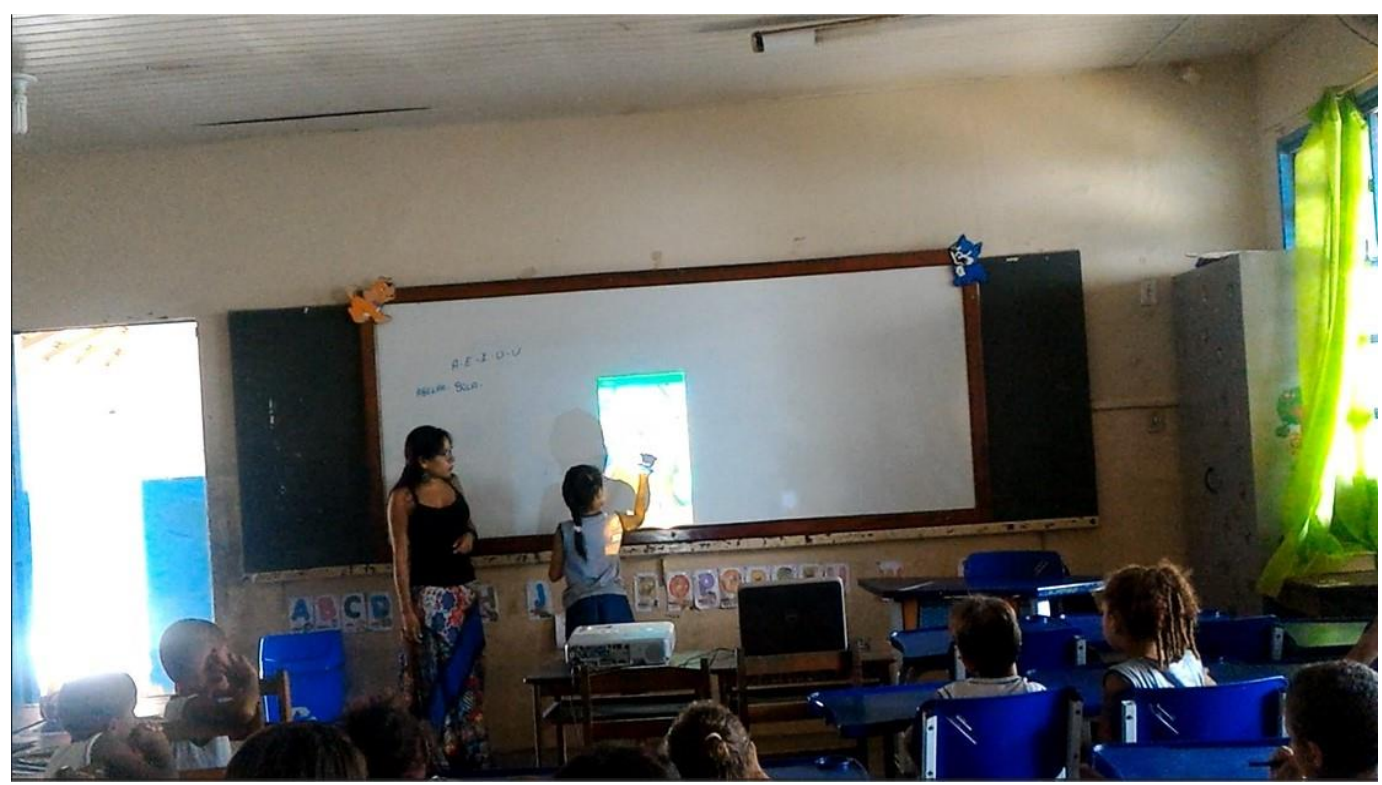

Figura 5. Participação dos alunos com ABC llustrado.

Ao final do estudo de caso que durou uma semana foi disponibilizado um questionário de avaliação do aplicativo, para duas professoras preencherem após a utilização do aplicativo em sala de aula. As perguntas foram feitas para saber se o aplicativo estava apresentando algum tipo de erros, se sua interface e agradável e fácil de usar, sugestão de melhorias, de que forma o aplicativo contribui para o aprendizado dos alunos, e se recomendaria para outros professores, através dessa avaliação foi possível ter uma visão mais ampla do ABC Ilustrado, visando identificar pontos que pudessem ser melhorados para que fosse corrigido o mais rápido possível, e também verificar se realmente as professoras ficaram satisfeitos com a ferramenta pedagógica para auxiliar o aprendizado das crianças.

Segundo as professoras que avaliaram o aplicativo, elas perceberam que o aplicativo não apresentava erros, tais com, travamento e fechamento sozinho do mesmo, e que sua interface era de fácil uso, que o aplicativo servia como ferramenta de apoio, as duas professoras ficaram satisfeitas com o aplicativo e recomendaria a outros professores.

Quando perguntadas sobre sugestões de melhorias, a professora aqui identificada como professora A, respondeu da seguinte forma, "O aplicativo é excelente para crianças em séries iniciais, como também para educação infantil e crianças 
especiais. Se for para acrescentar mais algo, sugiro as sílabas", outra pergunta abordada no questionário, foi "de que forma o aplicativo contribui para o aprendizado dos alunos?" a resposta da mesma docente se deu da seguinte maneira, "Trabalho com alfabetização, e o aplicativo é bastante útil, pois explora o alfabeto com letras e imagens e o nome da figura, além dos números que mostra o que o aluno nessa série necessita aprender. Também ensina as cores, formas e outros conteúdos muito importantes nessa faixa etária". A outra professora, aqui identificada como professora B, respondeu da seguinte maneira a respeito da sugestão de melhoria, "Personagens de conto infantil e cenário, pois chamam bastante atenção da criançada quando o desenho do aplicativo for com personagens de conto", sobre a contribuição para o aprendizado dos alunos a docente descreveu sua resposta com essas palavras "Uma vez que o aplicativo foi apresentado em sala de aula a criançada ficou mais concentrada e se mostraram interessadas no conteúdo visto pelos pequenos".

Dessa forma foi possível identificar que as professoras envolvidas no estudo de caso ficaram satisfeitas com uso dessa ferramenta pedagógica, não só as professoras mais os alunos também ficaram empolgados, concentrados e participativos nas aulas.

\section{Conclusão}

A atividade lúdica é fundamental para subsidiar o processo de construção do conhecimento e por isso é indispensável na prática educativa [Santos 2011]. Assim, as atividades desenvolvidas no aplicativo consideram as necessidades das crianças em aprender brincando e se divertindo, o aplicativo pode ser tanto usado em sala de aula como auxílio para os professores, ou em casa com os pais dos alunos ensinando seus filhos.

Neste artigo foi apresentado o aplicativo mobile ABC Ilustrado, cujo objetivo é auxiliar no ensino-aprendizagem das crianças que estão em fase de alfabetização de forma lúdica e divertida. $\mathrm{O}$ aplicativo disponibiliza oito categorias diferentes, as quais são apresentadas figuras, áudio descrição e músicas, nos quais os professores poderão explorar na sala de aula com seus alunos utilizando a metodologia que considerarem mais apropriada. Este aplicativo oferece alternativas para usar a tecnologia dentro da sala de aula auxiliando os professores, ou em casa, sendo necessário para a criança apenas um celular que tenha o sistema operacional Android.

Com a utilização do aplicativo espera-se trazer uma contribuição de apoio como recurso educacional nas séries iniciais, em relação ao ensino e aprendizagem desses alunos, pois tem uma função multidisciplinar, podendo ser utilizado dentro de vários contextos de acordo com as necessidades e realidades das turmas.

Portanto, o aplicativo ABC Ilustrado pode possibilitar múltiplas possibilidades para a aprendizagem, permitindo acesso ao conhecimento a qualquer hora e em qualquer lugar, além de promover a interação entre os educandos, melhorando até a maneira como eles se expressam.

A avaliação do aplicativo realizada pelas professoras da turma de $1^{\circ}$ série do ensino fundamental apresentou resultados positivos, pois, as mesmas ficaram satisfeitas com o uso da ferramenta pedagógica na sala de aula. As professoras sugeriram melhorias interessantes para serem implementadas no aplicativo, melhorando ainda mais 
VII Congresso Brasileiro de Informática na Educação (CBIE 2018)

Anais dos Workshops do VII Congresso Brasileiro de Informática na Educação (WCBIE 2018)

o ABC Ilustrado de acordo com a realidade das suas aulas e das turmas. A contribuição do aplicativo segundo as professoras foi positiva em todos os aspectos analisados, estimulando a interação entre professores e alunos, aguçando a curiosidade e a criatividade entre os mesmos, verificando-se o empenho e o desenvolvimento de cada um durante as atividades sendo executadas com o auxilio do aplicativo como ferramenta pedagógica.

Como trabalhos futuros, pretende-se, definir e implementar um website para gestão do ensino-aprendizagem, que possibilitará o acompanhamento da evolução dos alunos dentro do aplicativo, através de um quiz de perguntas e repostas sobre os assuntos abordados no mesmo, esse quiz contará com diferentes níveis de dificuldade que será implementado no ABC Ilustrado para ajudar nessa gestão. Com o website vai ser possível cadastrar as escolas, professores e alunos, acompanhar os alunos através de um ranking para saber quais alunos estão se destacando mais, gráficos com estatísticas que apresente as dificuldades dos alunos e em quais pontos eles estão se destacando mais. Além de criar um webservice com um banco de dados para salvar as informações dos alunos como por exemplo: nome, idade, gênero, turma, matricula, escola, login, senha e sua pontuação no quiz, o webservice possibilitara a integração do site com o aplicativo.

\section{Referências}

Almeida, F. J. (2012). Educação e informática: os computadores na escola (5a ed.). São Paulo: Cortez.

Bernardi, S. T. (2010), Utilização de Softwares Educacionais nos Processos de Alfabetização, de Ensino e Aprendizagem com uma Visão Psicopedagógica. Revista de Educação do IDEAU, v. 5 - n.10.

Junior, J. A. A, (2017). "Meu ABC Down: Aplicativo para Alfabetização e Letramento de Crianças com Síndrome de Down”. Dissertação. Universidade Federal da Paraíba.

Juttel, F., Kalempa, V. C, Pykosz, L. C (2015). “Alfabetizando Através da Realidade Aumentada: Desenvolvimento de Um Aplicativo de Auxílio À Alfabetização Utilizando a Realidade Aumentada Para Dispositivos Móveis”. Revista Tecnologias na Educação - Ano 7 - número 13.

Kobayashi, A. , Freire, F., Rocha, V., Scherma, A. (2015) "Língua de Gato: usando a linguagem de forma divertida", In: Anais dos Workshops do Congresso Brasileiro de Informática na Educação, p.463-470.

Mayer, R. E. (2005). "Principles for managing essential processing in multimedia learning: Segmenting, pretraining, and modality principles". The Cambridge handbook of multimedia learning, p. 169-182.

Ribeiro, V. M. (Org.) (2001). Letramento no Brasil: reflexões a partir do INAF 2001. São Paulo: Global, 2001. Dyer, S., Martin, J. and Zulauf, J. (1995) "Motion Capture White Paper", http://reality.sgi.com/employees/jam_sb/mocap/MoCapWP_v2.0.html,

Santos, J. O. (2011). O lúdico na Educação Infantil. Campina Grande: Realize. Disponível em: http://br.monografias.com/trabalhos3/ludico-educacaoinfantil/ludico-educacaoinfantil.shtml. Acesso em: 8 de fevereiro de 2018. 